\title{
Land Degradation in Nepal
}

\author{
Ramesh Dahal ${ }^{1}$ and Pradeep Adhikari ${ }^{2}$ \\ ${ }^{1}$ Proactive Research Services \\ ${ }^{2}$ City of Dallas
}

December 1, 2020

\begin{abstract}
Nepal is a mountainous country sandwiched between China and India that extends along the Hind Kush Himalayan range. The entire country sits on a geological formation that has witnessed massive transformation in the past several decades. Land degradation is active in Nepal. This study reviews the causes of land degradation in Nepal based on publicly available reports, books, journal articles, and government policy and regulations. The review also uses publicly available global datasets to contextualize local conditions. The review shows that topography; land use and cover change driven by population growth and urbanization; traditional agricultural practice in steep slope; soil erodibility due to unscientific ways of farming; use of chemical fertilizers and, pest and disease control techniques; unsustainable land management by the government; unscientific infrastructure development has been the proximate causes of land degradation in the majority of the cases. While underlying causes include population and poverty; out migration; deforestation; land tenure and property rights, non-farm employment; and technological change. The situation when combined with the Landslide Susceptibility Index and Land Cover data shows that the country needs to make concerted effort to stop and minimize the damage of land degradation in the country.
\end{abstract}

\section{Hosted file}

Dahal and Adhikari_LandDegration_in_Nepal_Main.pdf available at https://authorea.com/users/ 380366/articles/496388-land-degradation-in-nepal

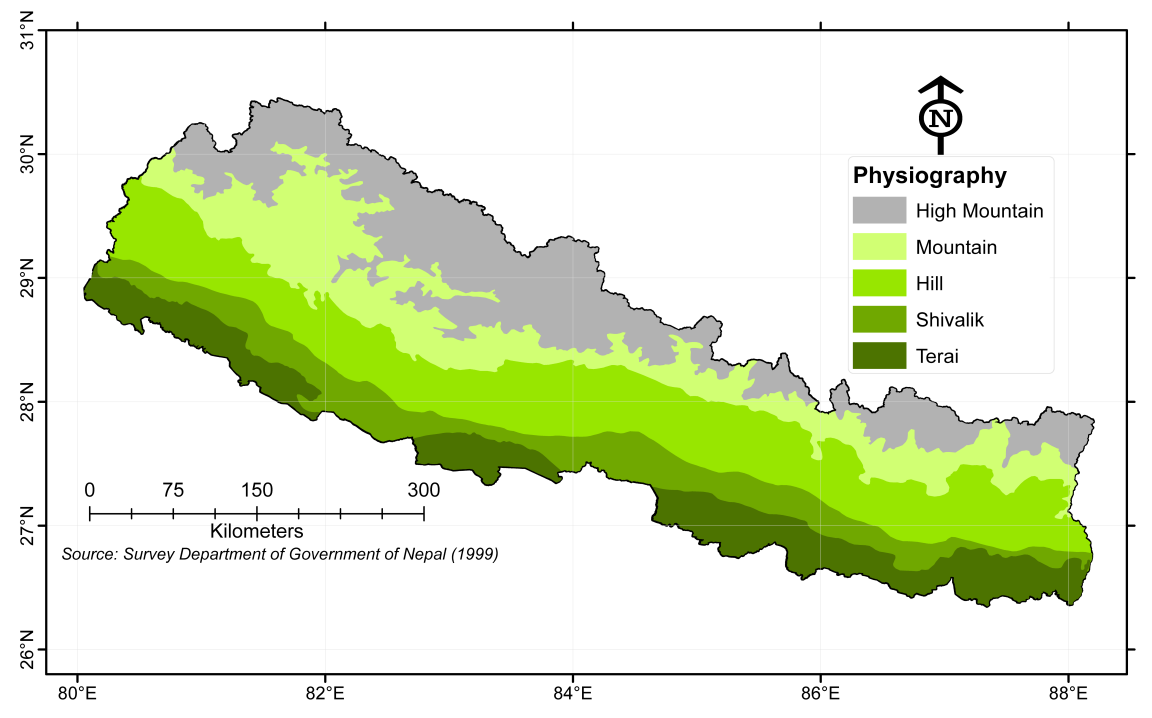



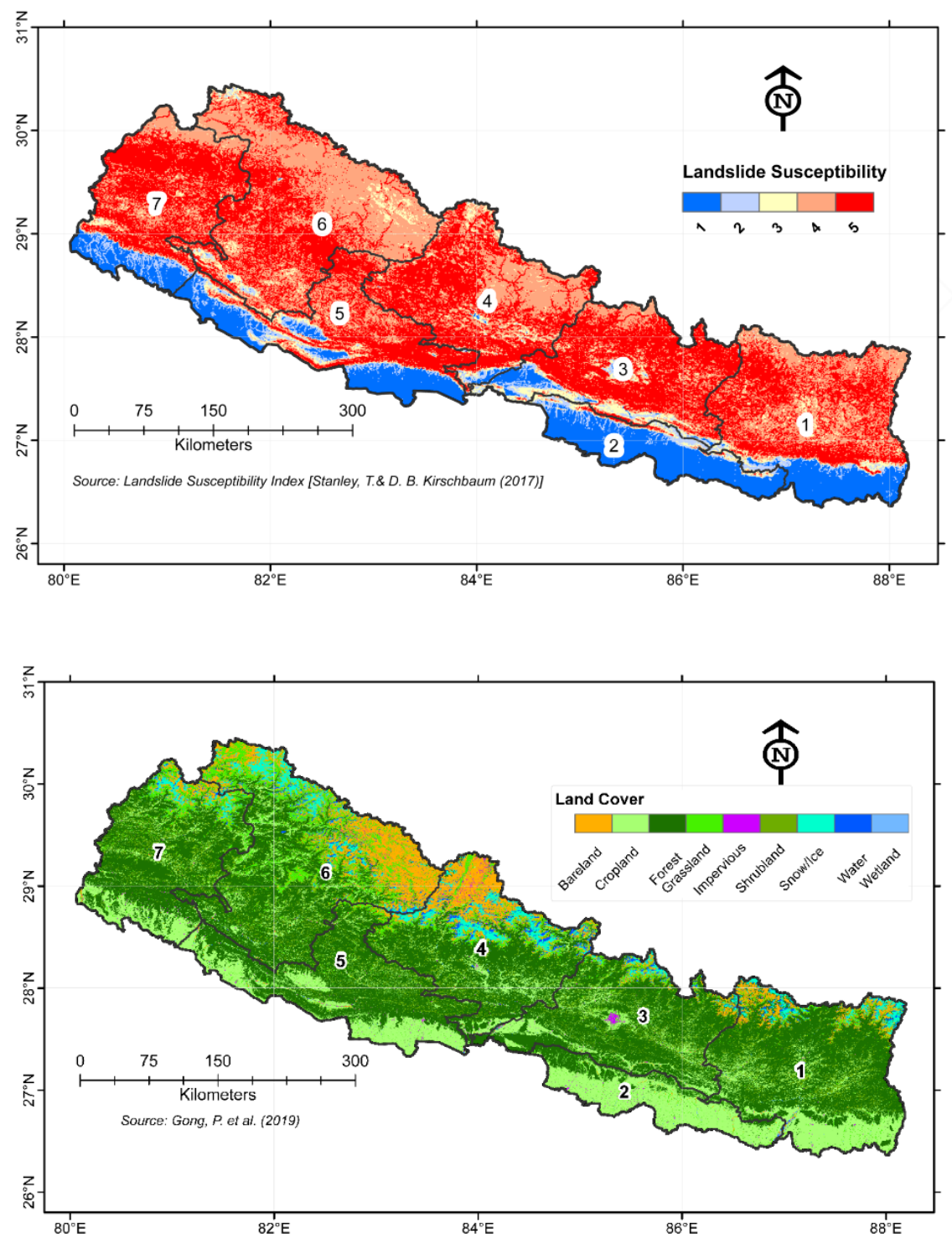

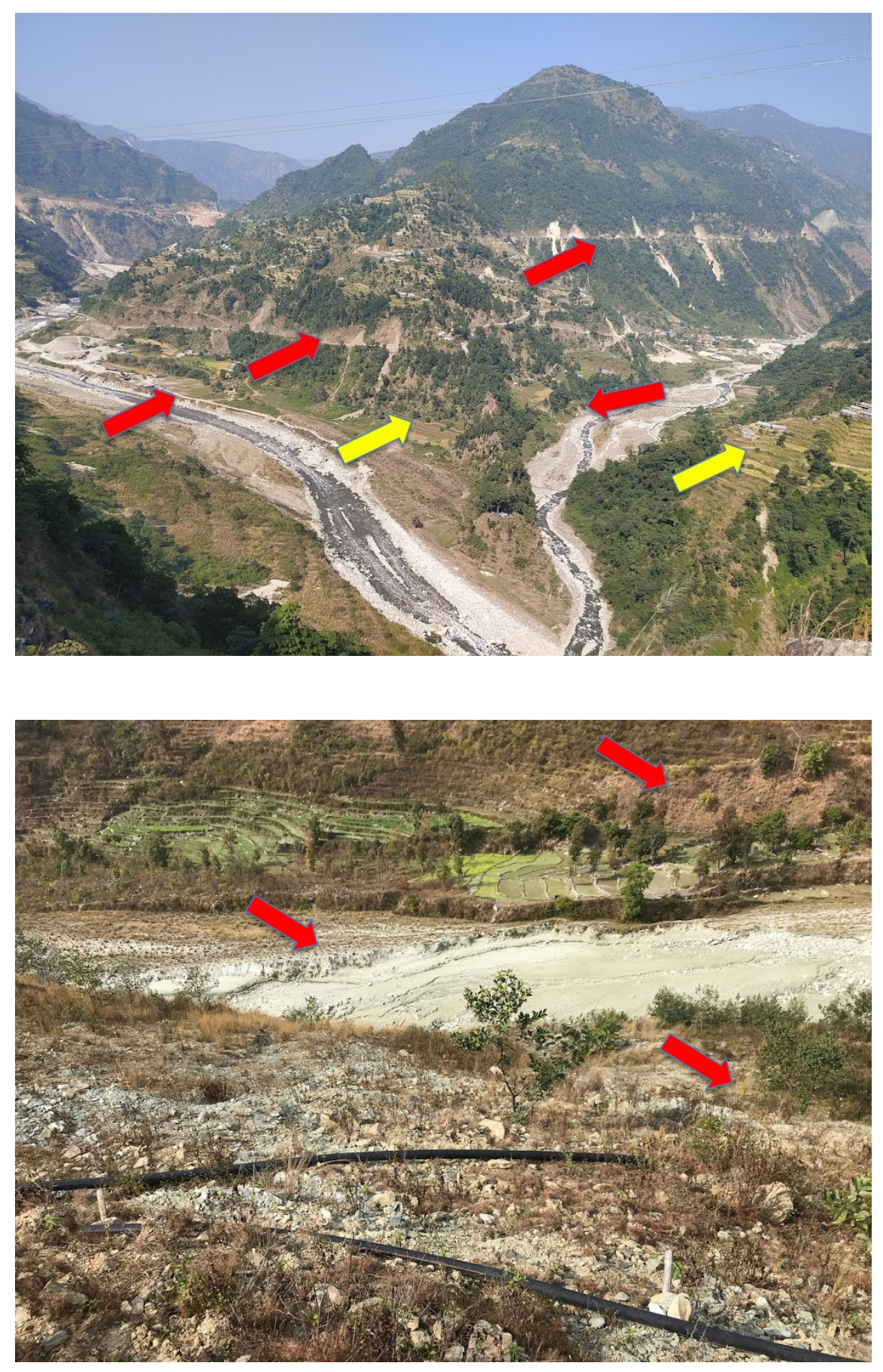

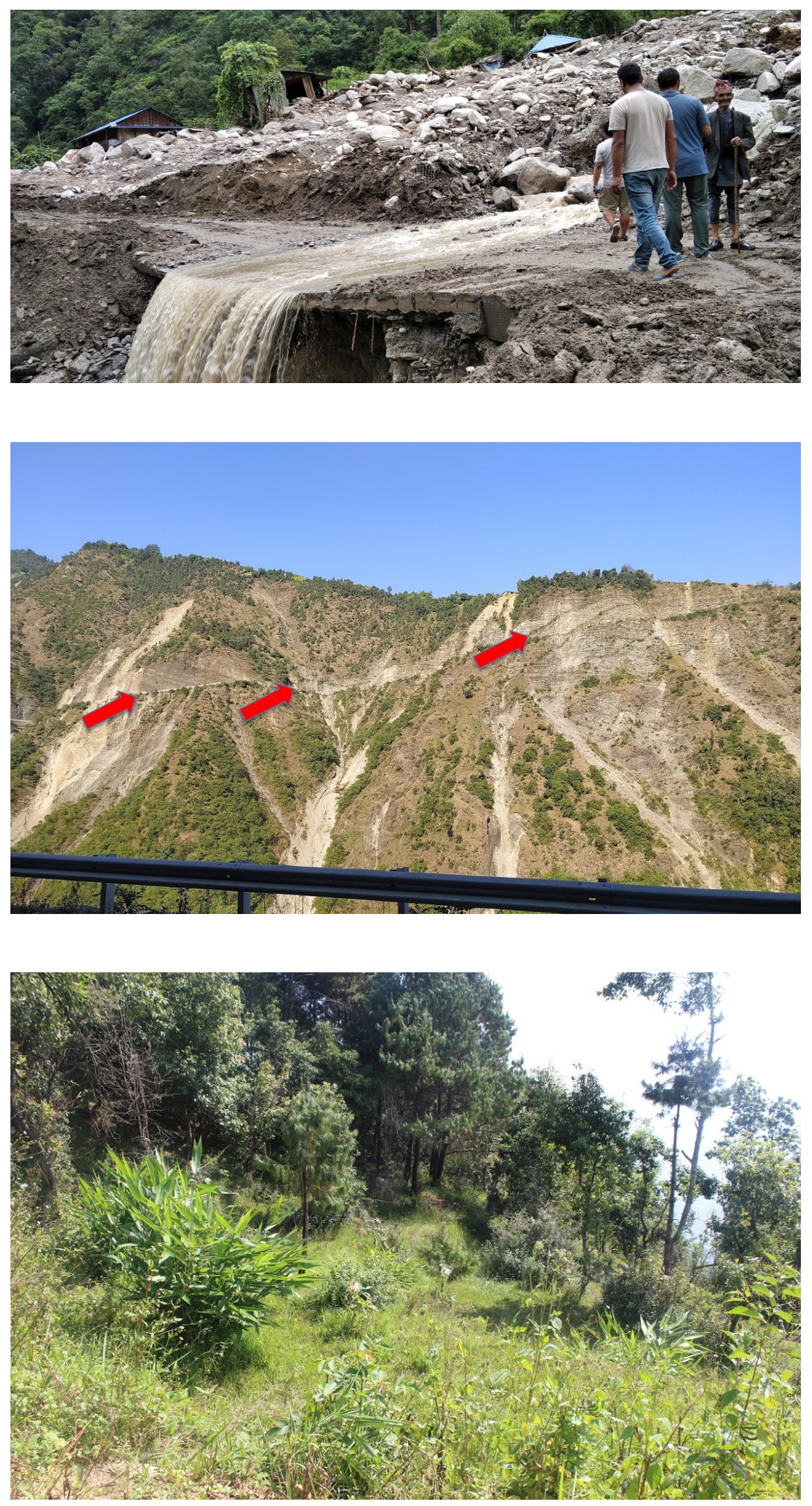


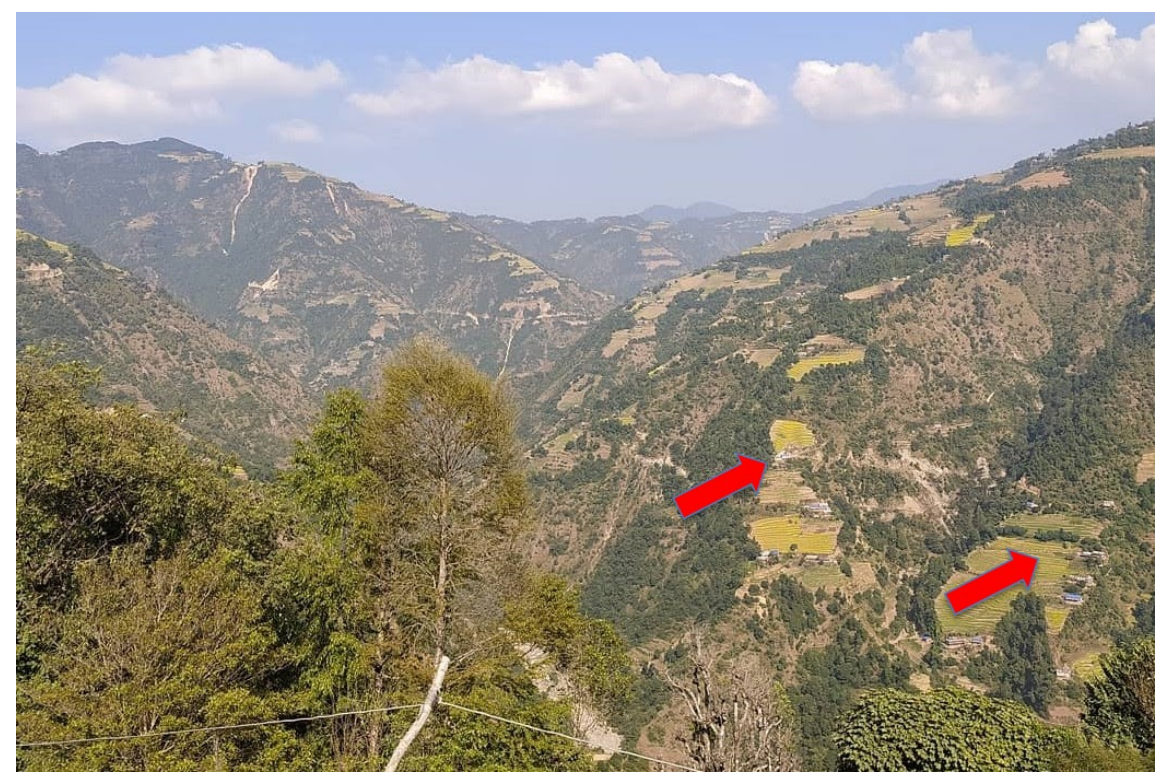

